\title{
AUTORIA E AUTORIDADE NO FAZER ANTROPOLÓGICO: COMO ENTENDER/EXPLICAR O RADICALMENTE "OUTRO"?
}

\author{
Melânia Nóbrega de Farias ${ }^{1}$
}

\section{Considerações iniciais}

Como reconhecer o "outro"? Chegamos à reposta de que para tal deve-se reconhecer também a si mesmo, uma vez que as identidades são construídas a partir da oposição eu/outro. Do contrário, a identidade (explicitamente "contrastiva") é dada por antonomásia.

Pensar o "outro" é, por excelência, tarefa da Antropologia. Constituída enquanto disciplina, tem se dedicado às mais diversas formas de pensamento e vida social que o homem foi capaz de criar e que, longe de surgirem e desaparecerem no nada, foram significativamente influenciadas pela cultura ocidental. Tão incorporadas a ela que se tornou impossível conhecê-la sem também dedicar-se ao estudo dos outros gêneros de vida e de pensamento que se espalham pelo mundo.

Ao longo de sua trajetória de análise dessas realidades sociais e culturais, os antropólogos têm adotado distintas perspectivas em relação a sua posição enquanto sujeitos do conhecimento e à dos objetos analisados, bem como em relação aos métodos de investigação mais adequados.

Mas quando a Antropologia decide remontar sua própria história, sai em busca da compreensão de si mesma, tal como costuma fazer com seus objetos de estudo. Por meio desse processo de "auto-estranhamento", o próprio sujeito da análise, ou seja, o antropólogo, transforma-se em objeto. O contexto estudado passa a ser o dos modos de viver, de pensar e de conhecer o "outro" que constituem uma determinada "cultura intelectual".

A partir destas primeiras reflexões, pretendo destacar dois pressupostos importantes da proposição deste trabalho: 1) que a discussão pretendida não é tão recente nas Ciências Humanas e 2) que a Antropologia, enquanto disciplina cientificamente reconhecida, fundamenta-se bem mais pela forma de observar do que pelo que se observa.

Desenvolver uma reflexão que inquira sobre o conhecimento oriundo da relação entre "sujeitos que observam" e "sujeitos que são observados" e a "autoridade" latente

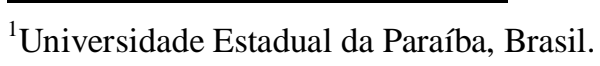


neste cenário levanta elementos que podem contribuir ao exercício do antropólogo, principalmente no que diz respeito às sujeições e escolhas da "vivência antropológica". Reconhecer a legitimidade da autocrítica dessa vivência (percebê-la epistemologicamente) apresenta-se como um dos grandes desafios da Antropologia.

O momento histórico da descolonização testemunha "deslocamentos" de “objetos de pesquisa" e "sujeitos que observam". Isso decorre da alteração do foco dos pesquisadores, que passam a desenvolver trabalhos sobre realidades mais "próximas". Sem sombra de dúvidas, os "sujeitos" legitimados a "serem observados" pela Antropologia passaram por mudanças.

À discussão que segue implica, até certa medida, reconhecer que os pares "objetividade" / "subjetividade" e "distanciamento" / "proximidade" são elementos constitutivos da cientificidade do "fazer antropológico" e de seu produto final, o texto. Em meio a essas polaridades, cabe ao pesquisador refletir sobre a construção do saber em Antropologia. A contextualização desse seu "sensível lugar" figura-se como enriquecedora para entender desde a construção de seus interesses até suas inferências sobre os dados produzidos.

Nesta discussão, que envolve "autoridade" e "poder" na relação pesquisadorpesquisado, não me limitarei a apenas autores denominados "contemporâneos", mesmo considerando que após a segunda metade do século $\mathrm{XX}$ antropólogos e nativos passaram a refletir as mudanças ocorridas nas relações políticas e econômicas entre os países dos quais tradicionalmente provinham uns e outros.

O fim do colonialismo alterou radicalmente a natureza da relação social entre os que perguntam e observam e os que são perguntados e observados. O declínio da confiança em fatos brutos, procedimentos preestabelecidos e conhecimento descontextualizado no campo das Ciências Humanas e, a rigor, do saber especializado em geral, alteraram não menos essencialmente a concepção que têm os indagadores e observadores daquilo que estão tentando fazer.

Esse período é marcado também pela alteração de papéis, já que os denominados "nativos" passaram também a serem reconhecidos como pesquisadores. Desde então se percebe uma busca constante para diluir a distância entre o "nós" (sujeitos que pesquisam) e o "eles" (sujeitos pesquisados), em um processo que chamo aqui de "qualificação de subjetividades", no qual se destaca a do pesquisador que, utilizando os termos de Geertz (2002, p. 170), teria uma "vida dividida", passando por uma "situação 
de migrante" (Bourdieu, 1998), que sendo (in)classificado tem que executar a denominada "dupla tarefa" (Da Matta, 1978): transformar simultaneamente o exótico em familiar e o familiar em exótico.

As Ciências Humanas vivem de mudanças, não apenas de "crises". Na Antropologia não é diferente. A maneira de percebê-la vem sofrendo questionamentos, evidenciados principalmente após meados do século XX. Neste período, para Geertz (2002, p. 173):

(...) um dos pressupostos em que se alicerçavam os escritos antropológicos, (...) - o de que seus objetos de estudo e seu público eram não apenas separáveis, mas estavam também moralmente desvinculados, e de que os primeiros deviam ser descritos, mas não convidados a se manifestar, e os últimos deviam ser informados, mas não implicados -, praticamente se desfez.

É pertinente reconhecer a implicação dos pesquisadores em suas pesquisas como um importante elemento a ser desenvolvido para perceber nossa disciplina de modo não tão rigidamente demarcado, definido ou circunscrito em seu "objeto", mas sim numa maneira particular de observar o que considerar ser a realidade. Oliveira (2000, p. 19) salienta que "seja qual for esse objeto, ele não escapa de ser apreendido [também] pelo esquema conceitual da disciplina formadora de "nossa maneira de ver a realidade"".

\section{Apresentando escolhas e uma trajetória}

Disponibilizar ao leitor referenciais que contextualizem o pesquisador e sua pesquisa são essenciais. Sendo assim, destaco que minha iniciação nas discussões sobre questão racial no Brasil teve como ponto de partida a minha graduação em Ciências Sociais na Universidade Federal da Paraíba (2001). Meu interesse pelas questões que envolvem "negros militantes", assim como "não-militantes" também pode ser percebido durante o Mestrado em Antropologia concluído na Universidade Federal de Pernambuco (2004).

Desde a graduação, minhas preocupações dizem respeito à maneira como são construídas as identidades negras. O plural, aqui, interessa, na medida em que se considera este processo de construção pautado pela pluralidade, negando-se, então, qualquer possibilidade de essencialização. Desse modo, acreditando, tal qual Maggie e 
Rezende (2002), que não há no Brasil "a" ou "uma" identidade negra, mas "identidades negras".

Na graduação tentei traçar um perfil do militante negro em Campina Grande/PB, buscando compreender como este se pensa a si mesmo, bem como de que maneira ele encara a ideologia racial nacional. Já no Mestrado, busquei entender a construção de identidades negras entre campinenses militantes e não-militantes. Pretendi perceber se esta construção existia e como ela se dava. A intenção era entender como negros que estavam e que não estavam ligados ao Movimento Negro se viam, como se entendiam e se definiam, como vieram a se construir como negros.

Desse modo, objetivei apreender a visão de negros campinenses sobre si, de modo que foi possível investigar diferenças nas construções identitárias entre negros militantes e não-militantes, e daí, pude entender o que leva e/ou o que não leva o indivíduo a assumir a luta política no que diz respeito ao negro, na medida em que foram relacionadas as trajetórias de vida de negros campinenses militantes e nãomilitantes à sua disposição ou indisposição a engajarem-se no Movimento Negro.

Expor de maneira sintética algumas de minhas preocupações servirão de base para desenvolver no tópico seguinte os elementos que considero importantes para situar minhas escolhas/sujeições durante parte de meu percurso acadêmico.

É importante atentar que o interesse de estudo está em constantes alterações, que implicam em desafios a serem superados. Acerca desse processo, Bourdieu (1989, p. 26-27) afirma:

A construção do objeto - pelo menos na minha experiência de investigador - não é uma coisa que se produza de uma assentada, por uma espécie de acto teórico inaugural, e o programa de observações ou de análises por meio do qual a operação se efectua não é um plano que se desenhe antecipadamente, à maneira de um engenheiro: é um trabalho de grande fôlego, que se realiza pouco a pouco, por retoques sucessivos, por toda uma série de correções, de emendas, sugeridos por o que se chama o ofício, quer dizer, esse conjunto de princípios práticos que orientam as opções ao mesmo tempo minúsculas e decisivas.

Percebe-se que a primeira dificuldade é a própria construção do "objeto". Situar o "lugar do pesquisador" pode denunciar uma outra dimensão não tão evidente: a importância das subjetividades no "fazer antropológico". Esta reflexão é pertinente para caracterizar minha situação enquanto pesquisadora "branca, de olhos verdes e cabelo liso", oriunda de família de classe média e manifestamente racista, que desenvolve 
pesquisas referentes a negros de origem bastante humilde e expostos cotidianamente a situações de preconceito e discriminação.

"Localizar o pesquisador" é fundamental para entender a sua construção particular, as dificuldades e os resultados da investigação. Ter consciência de quem, de onde, o porquê, como (o modo), e para quem o pesquisador fala serve para destrinchar armadilhas que consciente ou inconscientemente ele relega. Atento aqui para a importância da dimensão biográfica no "fazer etnográfico", visto que, a trajetória do pesquisador, suas opções teóricas e o contexto histórico-sociológico da pesquisa têm influência sobre escolhas, encaminhamentos, discussões e conclusões acerca do que observa.

Como já assinalou Peirano (1995, p. 137):

(...) hoje sabemos que a pesquisa depende, entre outras coisas, da biografia do pesquisador, das opções teóricas presentes na disciplina, do contexto sócio-histórico mais amplo e, não menos das imprevisíveis situações que se configuram entre pesquisador e pesquisado no dia a dia da pesquisa.

Para minha discussão neste artigo, destaco as seguintes questões: sendo eu "branca e de elite", que implicações tal vivência teria em minha pesquisa junto aos negros, em minhas escolhas e em minhas construções? No processo de pesquisa quem manipula e quem é manipulado? É pertinente considerar o jogo relacional do contexto de pesquisa em termos tão dicotomizados? Que desafios são estabelecidos nas relações pesquisador-pesquisado?

É importante, como sugere Mauss apud Bourdieu (2001), perceber que nas relações pesquisador-pesquisado existem arbitrariedades, que são manifestadas de diversas formas. Assim se expressa:

(...) tem na verdade um atributo essencial: seja um símbolo, uma palavra, um instrumento, uma instituição; seja mesmo uma língua, e até a ciência mais bem feita; seja ele o instrumento mais bem adaptado aos melhores e mais numerosos fins, seja ele o mais racional possível, o mais humano, ele é ainda arbitrário (p. 21).

Refletir sobre essa "arbitrariedade", que tem relação direta com a "autoridade" presente no "fazer antropológico", faz-se fundamental. Para tanto, parti da seguinte questão: por que diante de várias possibilidades no campo das Ciências Sociais, minha "escolha" foi desenvolver pesquisas junto à população negra? 
Reconhece-se que iniciar uma argumentação com uma pergunta cria expectativas que não se pode satisfazer a contento. No entanto, fazendo eco às palavras de Evans-Pritchard (2005, p. 243), "na ciência, como na vida, só se acha o que se procura". Depreende-se daí que "interesses de estudo" não "caem no colo" ou são impostos "goela abaixo", mas são construídos por sujeitos que, consciente ou inconscientemente, procuram, através destes, responder determinadas questões, considerando a operacionalidade de sua empreitada e seus desejos específicos.

Levando em conta que o autor não domina absolutamente todas as etapas de suas pesquisas (Clifford, 2002), mas que também não é dominado absolutamente por fatores exógenos em seu fazer e em suas escolhas, têm-se que perguntar como a investigação adquire sentido para os sujeitos envolvidos, inclusive para o pesquisador? Além disso, inquire-se: como trazer para o texto final, de forma clara, os processos que contribuem para dar sentido, para si e para os outros, a determinado interesse de investigação? Sem pretender dar respostas definitivas, vê-se que a manifestação de "estratégias de autoridade" é o elemento singular desse processo de consagração, que se consolida através da pertinência/relevância do trabalho.

Os interesses de estudo se enquadram num rol de escolhas conscientes a partir de pré-determinações que ultrapassam a intencionalidade e o controle pessoal. A consciência das escolhas não significa um domínio absoluto dos atos e das inumeráveis variáveis que a pesquisa de campo acrescenta à nossas "pré-noções".

Ao tratar de "redes de significados", Silva (2000) traz alguns exemplos sobre a relação entre pesquisadores (de níveis graduais diferentes), a qual põe limites e abre possibilidades de pesquisa. Tal reflexão parece oportuna por assemelhar-se a meu processo de aproximação da questão racial brasileira. Silva (2000, p. 28) ao comentar como certos intelectuais contribuíram para sua pesquisa faz lembrar das conversas que tive com minha tutora do Programa Especial de Treinamento (PET) em Antropologia da Universidade Federal da Paraíba no final da década de 90; com minha orientadora da graduação no início dos anos 2000 e com minha orientadora de mestrado entre os anos de 2002 a 2004, e que certamente tiveram influência em minhas escolhas até os dias de hoje. Passa-se a discutir alguns eventos singulares. 


\section{Algumas implicações do trabalho de campo e do trabalho acadêmico até aqui}

Tratando sobre o trabalho de campo, note-se que um dado interessante diz respeito à relação pesquisador-pesquisado. $O$ fato de eu ter uma determinada constituição física: branca dos olhos verdes, não despertou o espanto dos negros nãomilitantes, o que não aconteceu quando realizei a pesquisa entre os militantes. Os negros não-militantes me receberam com grande hospitalidade e tranquilidade em suas casas, não demonstrando nenhum tipo de desconforto com a minha presença. Aliás, mesmo depois de terminado o campo entre os não-militantes, quando retornei ao bairro do Monte Santo (o qual, de acordo com os dados do Instituto Brasileiro de Geografia e Estatística (IBGE), é um dos bairros mais pobres de Campina Grande) para visitas particulares, escutei vários comentários positivos feitos pelos não-militantes entrevistados e repassados pelos amigos que ia visitar, sobre a minha pessoa.

Tais comentários referiam-se à boa educação que os não-militantes reconheciam na minha pessoa e à minha boa índole. Além disso, estes comentários também estavam relacionados à "capacidade de tratar bem" que eles me imputavam.

A postura dos negros não-militantes em relação a mim parece ter se constituído no sentido de me ter como "uma pessoa de casa". Várias foram as vezes em que saí de suas casas carregando biscoitos caseiros e mesmo a garantia de que poderia voltar, mesmo que não fosse para tratar de entrevistas e histórias de vida. Esses gestos surtiram em mim o efeito de demonstrações de aceitação, de que eu não os oferecia perigo. Isto provavelmente se tenha dado porque acreditassem que não teria porquê para eu lhes ameaçar, na medida em que não se sentem na condição de ter que provar nada para ninguém.

O interessante é que esta postura mantida pelos não-militantes não significa que não assumam sua identidade negra e/ou que tal postura seja um reflexo de uma "harmonia racial", como sugerem algumas obras publicadas no Brasil ${ }^{2}$. Longe disto, esta postura assumida pelos negros não-militantes campinenses está relacionada com o tipo de construção identitária que acionam em suas relações cotidianas, estando aí presente, o seu "ser negro(a)".

\footnotetext{
${ }^{2}$ A obra precursora sobre a existência de uma "harmonia racial brasileira" é tributada a Gilberto Freyre com a publicação de "Casa Grande e Senzala" (1936).
} 
Já os militantes, tanto na pesquisa feita em 2001, ao concluir minha graduação, quanto na pesquisa feita para o Mestrado em 2003, não me receberam em casa ${ }^{3}$ e alguns deles chegaram a revelar grande surpresa e inquietação com a minha presença durante as entrevistas.

Ao me encontrar com um dos militantes para uma entrevista, o mesmo ofereceume um café. Por recomendação médica, tinha que evitar consumir café em demasia, por isso recusei e agradeci. Para minha surpresa, o militante respondeu-me com uma indagação: "Por quê? Por que é preto?". Senti um estranhamento enorme diante desta situação e ao chegar em casa fiquei me questionando se fizera sentido explicar-lhe que tinha sido proibida pelo médico, como o fiz.

Além disso, ao final da entrevista, fui novamente surpreendida com um: "Olhe, quando quiser, me dê notícias, pois moro em frente a um restaurante e posso te levar lá. Sabia que negro também vai a restaurante?’. Dessa vez, calei-me e não respondi. Apenas fiquei em dúvida se isso seria um convite lisonjeiro ou uma demonstração de hostilidade. Logo conclui que tal atitude era um misto de hostilidade e tentativa de mostrar que "era negro e capaz de".

Como também houve outras colocações que nos remetem a este mesmo sentido.

\begin{abstract}
"Eu sou muito proposital, eu assumo essa postura de cara que adora ser negro, eu me sinto bem, eu gosto de ser essa bandeira negra, eu gosto de saber que sou negro, eu gosto de saber que eu sou obrigado a estudar, por mais que eu não queira, eu gosto de saber que as pessoas quando olham pra mim eu imponho respeito, porque eu imponho medo, porque é lógico, todo mundo quando olha pra (...) diz assim 'Ó, melhor você não cutucar o cara, porque esse cara vai mandar chumbo em você', e mando mesmo e estudo pra isso e vivo consciente pra isso, não que eu queira atacar ninguém, mas na verdade quando eu me sinto atacado eu revido e revido com força (...) eu particularmente me preparo sempre e eu não vou ser hipócrita de dizer 'não eu sempre me preparo', eu sempre olho as pessoas brancas, dentro de mim é já uma necessidade de olhar já com um olho 'opa, pera aí', eu sempre me preparo já pra uma gracinha qualquer, porque nós sabemos que tem isso.” (m 5)

"Olha, há quem diga por aí que o (...) é anti-branco, acho que em primeiro lugar nós somos agredidos neste país há mais de 400 anos, evidentemente que a gente não pode só levar pancada, a gente tem que bater um pouquinho no sistema brando e se eu pudesse criar hoje uma universidade só para negros eu criaria, qual é o problema? (...) eu acho isso salutar, eu acho isso saudável para o nosso desenvolvimento político negro.” (m 2).
\end{abstract}

\footnotetext{
${ }^{3}$ As entrevistas feitas com os militantes negros campinenses foram feitas em seu ambiente de trabalho.
} 
Teixeira (1998) propõe que as mais frequentes atitudes tomadas com relação à discriminação são no sentido de tentar impedi-la ou evitá-la, o que revela uma visão de que a melhor defesa é o ataque, mostrando que se é "bom" ou diferente". Por outro lado, toda e qualquer atitude deve partir de um princípio que vá de encontro à negação de uma "cultura de discriminado", que parece determinar o perfil dos que se submetem sem reação, abaixam a cabeça ou não se impõem como indivíduos numa sociedade de iguais, como também reza a ideologia em torno da formação da sociedade brasileira e manda o bom credo igualitário "que domina o nosso sistema jurídico e legal, a começar pela nossa carta constitucional".

Sendo assim, é possível perceber que a pesquisa antropológica não é algo de fácil realização. Exige preparo para que se possam reconhecer, em campo, as nuances existentes nas entrelinhas da relação pesquisador/pesquisado e, com isso, tentar dirimir os possíveis conflitos ou "contaminações" que tal encontro possa ensejar. As questões de poder estão inerentes às relações sujeito/objeto do conhecimento e não são dadas verticalmente, mas, sim, horizontalmente.

A relação pesquisador/pesquisado envolve questões onde estão presentes a troca; a tolerância; a reciprocidade e a cumplicidade - "coisas" impossíveis de se manifestarem sem o outro com quem se dialoga. O poder é visto - nessa relação - como algo extremamente maleável, visto que pode ser acionado tanto pelo pesquisador quanto pelo pesquisado. O primeiro pode aparentemente estar imbuído de uma autoridade científica e, talvez por isso, pense "controlar" a situação; o segundo, no entanto, tem as informações desejadas pelo primeiro, e as fornece - por vezes - a conta-gotas; ou conforme lhe for mais cômodo ou proveitoso.

Não se quer dizer, desse modo, que todas as interações configuram-se como um possível comércio de bens materiais ou simbólicos. Mas é inegável que ocorrem, consciente ou inconscientemente e - muitas vezes - à revelia do "controle" científíco que o pesquisador acredita ter em campo, ou seja, dos bias existentes na inter-relação. $\mathrm{O}$ que se tem é uma atribuição de agência ao sujeito pesquisado: ele não é um mero autômato a reproduzir uma programação que lhe foi, supostamente, impingida pelo simbólico.

Levando em conta as considerações acima colocadas, considero que consegui manter uma relação de confiança com a maioria dos militantes e com os não-militantes, 
a ponto de ter acesso a informações que poucos têm, mesmo acreditando que deve haver uma "distância necessária" entre o pesquisador e seu objeto.

Porém, não é apenas no trabalho de campo que tenho enfrentado o estranhamento. Desde 1998, quando comecei a estudar a construção de identidades negras, tenho me deparado com o espanto dentro da Academia em relação à minha escolha e a minha postura diante do meu objeto de estudo.

Uma constante em minha trajetória acadêmica tem sido a pergunta: "Como você estuda negros, sendo você branca?". Na maioria dos eventos acadêmicos onde apresento meu trabalhos essa questão me é formulada. Percebe-se, então, que a reação dos estudiosos ao ver uma branca estudando negros caminha no sentido de colocar-me como a "pesquisadora que estuda seu radicalmente oposto: o "exótico"”.

Sendo assim, de tanto ouvir tal indagação, passei a refletir mais a fundo sobre a mesma. Hoje em dia passo a encarar meu "lugar" em meio a essa alteridade de forma mais segura, pois até a bem pouco tempo me surpreendia comigo mesma ao perceber que me colocava à prova diante de minhas análises e posicionamentos. Vale ressaltar que na Antropologia Brasileira, onde historicamente se tem privilegiado o estudo da sociedade do pesquisador, o processo de entender o outro que pertence a nossa cultura nos conduz quase que inevitavelmente a pensar criticamente sobre a relação pesquisador-pesquisado e sobre o lugar desse outro e o nosso na sociedade.

A segurança mencionada acima foi adquirida a partir da reflexão atenta acerca da alteridade na Antropologia. Assim, vemos que o modelo antropológico clássico de entendimento do outro inaugurado por Bronislaw Malinowski previa que as etnografias deveriam carregar consigo uma consciência sobre a diversidade do mundo, revelando em seus textos a ideia de um outro radicalmente diverso de nós. Por outro lado, ao demarcar a diferença e a distância entre as culturas e, com isso, a impossibilidade de que uma fosse avaliada em função dos valores e da visão da outra, acabou-se paradoxalmente dificultando a possibilidade de se trabalhar a diferença como crítica cultural, com efeito, uma das bases em que se assentou a antropologia da década de 20 , por exemplo, na crítica ao racismo.

Através desse modelo o lugar do "pesquisador" e do "pesquisado" ficaram bem definidos: o pesquisador, treinado academicamente, saía do seu contexto de origem e encontrava o pesquisado, distante, iletrado, frequentemente além-mar. Depois de passar algum tempo junto a algum grupo estranho, retomava a sua origem e escrevia textos em 
que retratava culturas como um todo. Como coloca Lacerda (2003), esse modelo perpassou os três paradigmas tradicionais da disciplina: o racional-estruturalista, o estrutural-funcionalista e o culturalista, vindo a ser contestado pelos pós-modernos.

Em meados da década de 60 os pós-modernos passam a encarar a pesquisa de campo não mais como uma fórmula, mas como um fenômeno histórico, inserida num contexto biográfico, político e teórico, o que implica diferenças de abordagem dependentes do momento histórico. Desse modo, a cultura passa a ser vista como um texto na perspectiva de Geertz (1978), e não mais como um todo integrado, sendo tarefa da antropologia o exercício de sua interpretação e crítica. Além disso, com os pósmodernos passa a ter lugar a polifonia, o diálogo e o objetivo final, no que diz respeito ao autor, passa a ser fazer com que ele se dilua no texto, minimizando em muito sua presença, dando espaço aos outros, que antes só apareciam através dele.

A posição do autor, assim, é relativizada. Ele não é mais aquele que re-elabora uma experiência para explicitar a realidade de uma cultura com uma abrangência e coerência impossíveis para aqueles que a vivem no cotidiano. Não é mais um sujeito cognoscente privilegiado, mas igualado ao nativo e tem que falar sobre o que os iguala: suas experiências cotidianas. O ponto de vista nativo torna-se então meta inalcançável. As vozes são todas equiparadas e o que se representa são sujeitos individuais, não papéis sociais. O que o antropólogo pode fazer é inscrever processos de comunicação em que ele é apenas uma das muitas vozes.

Dessa forma, vê-se que o material etnográfico sobre o qual a Antropologia trabalha é resultado da atividade do pesquisador, que se encontra num momento específico de sua trajetória pessoal e teórica e do contexto dado, bem como do momento em que se encontra o grupo social em que ele estuda em seu próprio processo de transformação. Logo, a experiência pessoal pela qual passa o pesquisador e os dados que ele coleta não estão completamente dissociados.

Portanto, acredito que não é preciso “tornar-me uma igual, o próprio outro”, para que esteja apta a estudar o processo de construção de identidades negras, mesmo porque a barreira física seria a primeira a impor-se à minha frente. Não desconsidero que a diferença entre mim e meus informantes exista nem que ela acarreta determinadas relações intersubjetivas. No entanto, não encaro essa diferença enquanto um obstáculo, um complicador ou mesmo uma impossibilidade. Muito pelo contrário, vejo essa diferença como constituinte do processo de construção do próprio texto e como algo 
rico ao meu entendimento sobre mim mesma e sobre os meus informantes e vice-versa. Por isso, considero pertinente terminar esta reflexão colocando aqui a citação feita por Lacerda (2003) da obra de Pierre Bourdieu:

\begin{abstract}
O etnólogo deve afirmar a identidade para encontrar as verdadeiras diferenças. Estou convencido de que uma certa forma de etnocentrismo pode ser a condição para uma verdadeira compreensão, se designarmos assim a referência à sua própria experiência, à sua própria prática e desde que, evidentemente, esta referência seja consciente e controlada. Nós gostamos de nos identificar com um alter ego entusiasmado. É mais difícil reconhecer nos outros, tão diferentes na aparência, um eu que não queremos reconhecer. Deixando então de ser projeções complacentes em maior ou menor grau, a etnologia e a sociologia levam a uma descoberta de si mesmo através da objetivação de si exigida pelo conhecimento do outro. (p. 59)
\end{abstract}

Desse modo, o texto etnográfico, como representação do campo e das relações que nele se dão, pode ser, portanto, menos o resultado "final" de uma pesquisa, e mais um meio para a melhor compreensão dos valores do outro, considerando o fato de que estes valores são interpretados por alguém que também não se despe de seus próprios valores e subjetividades, e fala para terceiros, desconhecidos, de modo generalizante, ainda que "cuidadosamente".

Observa-se que o mito do "pesquisador fantasma", despido de seus afetos e desafetos, não é condizente com nenhuma situação de investigação antropológica. A subjetividade do pesquisador é inerente a qualquer pesquisa, em qualquer época, e o simples (que não é tão simples) (auto)reconhecimento desta especificidade deve ser considerado de fundamental importância.

Ao elaborar o texto final, ao "estar aqui" nos termos de Geertz (2002), associamse "estratégias de autoridade" conduzidas por "jogos de linguagem", nem sempre conscientes, mas que buscam imprimir sentido ao conteúdo. Nesses “jogos” é importante evidenciar alguns elementos constitutivos daquele que fala/escreve. Cardoso de Oliveira (2000, p. 66) afirma que se "as condições do trabalho de gabinete" já são por si problemáticas por envolver a "dinâmica dos jogos de linguagem, próprios de nossa disciplina e das congêneres", não podemos furtar-nos de uma "atitude crítica, ou melhor, autocrítica". Nesse sentido, através da contextualização reflexiva sobre o interesse de estudo, poderíamos evidenciar, no campo dos "jogos", as "estratégias de autoridade" em suas diferentes formas de manifestação. 
Clifford (2002), ao discutir sobre a "autoridade etnográfica" do pesquisador, problematiza a influência que os "sujeitos que são observados" tem sobre o pesquisador/autor e o não controle total deste sobre os (seus) dados. Não se discorda que tal influência possa proceder, porém é importante atentar que quem faz a seleção deste "outro", potencialmente influente, é o próprio pesquisador, mediante relações construídas (com) e dos (re)conhecimentos dos "sujeitos que são observados. Assim, o autor mesmo sendo influenciado, conserva/mantém ou tenta conservar/manter certo "controle" e "autoridade" sobre o dito, pois, diferentemente da autoridade potencialmente exercida por seus "interlocutores", é ele que, na textualização final, fará a seleção que imprimirá um certo sentido (particular) ao texto e sua consequente inteligibilidade.

É difícil negar (ou ao menos desejar) que a dialogicidade, a polifonia, as textualizações difusas e outros elementos estão presentes no "fazer antropológico". Clifford (2002, p. 54) diz inclusive que "se a etnografia é parte do que Roy Wagner (1980) chama de 'a invenção da cultura', sua atividade é plural e além do controle de qualquer indivíduo". Cabe enfatizar que o autor em questão problematiza um pretenso controle absoluto ("autoritarismo") do pesquisador sobre o "fazer antropológico" e não a sua "autoridade", visto que sem certa dose desta "autoridade" dificilmente seria possível dar sentido a elementos que para determinados públicos, inclusive para o próprio autor, são por vezes ininteligíveis.

Portanto, reconhecer a importância da subjetividade do pesquisador como um elemento constitutivo da investigação e da construção do saber e esmiuçá-la não implica confinar a Antropologia à experiência pessoal do pesquisador, nem a repartir a "autoridade etnográfica" com seus informantes, nem negar à disciplina seu específico estatuto de ciência, mas alimentá-la com um elemento ainda pouco reconhecido, a "autoridade" inerente na construção desse saber.

Atentar que a experiência do pesquisador é um dado antropológico não implica necessariamente pretender tornar simétrica a relação pesquisador-pesquisado. Percebese, entretanto, que há demandas e contextos nos quais se exigem "hierarquia" e "autoridade" para possibilitar inteligibilidade. Ao problematizar a questão da "autoridade" que se coloca na relação pesquisador-pesquisado tem-se a pretensão de evidenciar a necessidade de seu reconhecimento. Se, como coloca Bourdieu (1989, p. 
111), para conhecer e necessário classificar, para classificar não seria necessária uma certa "autoridade" da parte do pesquisador?

Por fim, acrescenta-se que a reflexão sobre a prática do pesquisador tem em si mesma seu potencial criador, numa disciplina que pode nem sempre levar a resultados que assegurem certezas estáticas, mas instauram inquietações construtivas.

O incentivo a exercícios reflexivos como o intentado neste artigo, para além de qualquer "momento antropológico", "escola", "paradigma" ou "modelo" está na base da disciplina e da metodologia antropológica. Esta base (o "trabalho de campo" em Antropologia, o "estar lá" como denomina Geertz (2002), o "olhar diferenciado") a distingue de outras ciências na medida em que o pesquisador não executa uma coleta de dados pura e simples, mas vivencia uma experiência que o afetando produz os dados sobre os quais se dará a reflexão. Sendo assim, o pesquisador é elemento constitutivo de sua própria produção, como o que tem acontecido em minhas pesquisas até aqui, por isso é necessária uma vigilância constante e declarada, já que a amplitude ou profundidade de tal experiência dá ao trabalho de campo um significado especial, uma vez que o principal instrumento da pesquisa é o próprio pesquisador na consciência de si mesmo.

Finaliza-se, salientando que a discussão traçada até então reconhece a existência de limites e desafios na pesquisa e na "razão científica", em geral, e na "cientificidade" da disciplina antropológica, em particular, principalmente no que diz respeito ao "tornar evidente" as subjetividades do autor e percebê-la epistemologicamente. Todavia, é pertinente ressaltar que, como coloca Oliveira (2000, p. 65) fazendo alusão a Habermas, é necessário continuar acreditando na razão, uma vez que a modernidade não pode ser considerada esgotada para se "levar tão a sério" a dita pós-modernidade.

\section{Considerações acerca de um fim que ainda está por vir}

No Doutorado proponho um estudo sobre a questão da inclusão de alunos (as) negros (as) na Universidade Estadual da Paraíba (UEPB) através da Política de Cotas Sociais da Instituição e suas trajetórias. O que se pretende compreender é, em última instância, como estes alunos (as) se veem enquanto negro (as) e "cotistas", quais os caminhos percorridos por estes (as) até chegar à UEPB e ainda perceber suas trajetórias no âmbito da UEPB. 
O fato é que, segundo Teixeira (1998), nenhum autor questiona a relação entre raça ou etnicidade e as desigualdades sociais. $\mathrm{O}$ que, parece, perpetuaria esse estado de coisas seria o fato de que também o negro ver-se-ia "excluído" das possíveis aberturas que a estrutura social ofereceria à mobilidade social ascendente, via sistema formal de ensino e mercado de trabalho.

Desse modo, ao iniciar mais um empreendimento de pesquisa em minha trajetória acadêmica, considero importante levar em consideração aquilo que Zaluar (1988) aponta como: vários problemas que permanecem não resolvidos com respeito à posição do observador.

A autora supracitada coloca as seguintes questões: "seria ele um líder, um educador, um dirigente, ou um mero catalisador?"; como, enfim, diante das demandas impostas no processo de interação, exerceria ele as atividades de pesquisador? Zaluar (1988), então, alerta para a negação da tensão sujeito/objeto nas entranhas de um projeto político que une observador e observado, trazendo ao contexto uma falsa indistinção entre um e outro.

Desse modo, segundo a referida autora, "ao se negar o posto de observador e ao avalizar (participativamente) ações e pessoas, o pesquisador pode estar inadvertidamente legitimando lideranças locais, tanto de pessoas quanto de grupos" (p. 113); e pode, ao mesmo tempo, ajudar "a instituir o próprio modo de comunicação entre lideres e liderados" (idem). Fazendo isso, tem-se a possibilidade de dar força a um tipo de retórica e, mesmo, um tipo de liderança, que pode estar distante de ser a única capaz de mobilizar e organizar o espaço público.

Assim, conforme salienta Zaluar (1988), a simples presença do pesquisador junto a uma associação ou a um grupo de pessoas - como é o caso dos(as) cotistas negros(as) - pode vir a aumentar o prestígio e a força delas no campo político das demandas por acesso e manutenção de políticas afirmativas internamente na UEPB. No entanto, o poder, nessas situações, é uma via de mão dupla. Dado o fato de os "nativos" também fazerem uso do pesquisador enquanto instrumento de barganha; ou seja, não há inocência na relação pesquisador/pesquisado na interação em campo. O que se tem são jogos de interesses onde as demandas - tanto de um quanto de outro - configuram-se em meios de obtenção do que é desejado, seja uma entrevista, acesso aos espaços interditos, confidências, segredos ou, simplesmente, o prestígio que se supõe ter um 
intelectual acadêmico, valendo, neste caso, ressaltar que atuo como professora do quadro permanente da UEPB.

Zaluar (1988, p.117) adverte que a pesquisa não precisa trazer - como realmente não traz - vantagens materiais imediatas ao pesquisador. Contudo, nessa troca de “coisas” palpáveis e não palpáveis, o pesquisador é quem recolhe maiores dividendos: escreve livros; conclui dissertações e teses; aumenta o seu leque de oportunidades de emprego dentre outras vantagens. São questões que não devem estar ausentes na reflexão que leva em conta a relação pesquisador/pesquisado, as quais pretende-se considerar quando do trabalho de campo voltado para o Doutorado.

Desse modo, a perspectiva tanto das pesquisas realizadas em momentos anteriores quando a que se pretende agora no Doutorado coaduna-se com a visão de Barth (2000) sobre a análise da cultura.

Em "A Análise da Cultura nas Sociedades Complexas", o supracitado autor preconiza um olhar sobre a cultura que leve em consideração sua totalidade e que seja capaz de abstrair tanto o seu funcionamento quanto suas "controvérsias". Um dos argumentos que leva Barth (2000) a tal perspectiva é a consideração de que a realidade das pessoas é composta de construções culturais (visão simbólica de cultura) sendo necessário explorar empiricamente o grau de padronização e a diversidade de fontes desses padrões, uma vez que segundo o autor: "precisamos desenvolver outros modelos que permitam apreender de modo mais direto e preciso as características observadas, sem um filtro que negue tudo aquilo aparentemente inadequado" (p. 113).

Assim, ao abordar as diferentes autoridades presentes na vida social balinesa, Barth (2000) propõe que o antropólogo deve esperar da realidade uma multiplicidade de padrões parciais, "que interferem uns sobre os outros, e se estabelecem em diferentes graus nas diferentes localidades e nos diferentes campos; e que devemos duvidar de toda afirmação de coerência, salvo quando tiver sido devidamente demonstrada" ( $p$. 120).

A intenção de Barth (2000), pois, é descobrir e mapear as formas significativas de coerência na cultura, não através de formas e configurações ${ }^{4}$ (ou estrutura como

\footnotetext{
${ }^{4}$ Aqui se faz referência ao conceito de configuração na obra de Norbert Elias, o qual pode ser compreendido através da leitura de sua obra Introdução à Sociologia, publicada em 1980, em Lisboa, pela editora Edições 70.
} 
almeja o estruturalismo lévi-straussiano ${ }^{5}$, por exemplo), "e sim pela identificação de processos sociais e pela observação empírica de suas consequências, isto é, pela elaboração de modelos do seu modo de operar. Devemos ser capazes de identificar as partes envolvidas nos discursos que se dão, e o 'segmento do processo do mundo infinito e sem sentido sobre os quais elas conferem significado e sentido"” (p. 127-128).

Para Barth (2000), “os atores estão (sempre e essencialmente) posicionados”: as diferentes posições constituem a conversação dentro da comunidade, onde as pessoas interpretam e compartilham suas experiências e conseguem entender melhor suas próprias vidas e de outras pessoas. Leva-se em conta que os indivíduos não possuem uma consciência e um horizonte que abranja a totalidade da sociedade, das instituições e das forças que as atingem. Sendo assim, coloca o autor:

Contudo, de alguma maneira, ao vários horizontes limitados das pessoas se ligam e se sobrepõe, produzindo um mundo maior que o agregado de suas respectivas práxis gera, mas que ninguém consegue visualizar. A tarefa do antropólogo ainda é mostrar como isso se dá, e mapear esse mundo maior que surge (Barth, 2000, p. 137).

De acordo com Barth (2000), é possível afirmar que cada pessoa está "posicionada" em virtude de um padrão singular formado pela reunião, nessa pessoa, de partes de diversas correntes culturais, bem como em função de suas experiências particulares. Desse modo, para construir a dinâmica interna de cada uma dessas correntes, é necessário separar certos aspectos da pessoa e os ligarmos a partes de outras pessoas, formando organizações e tradições englobantes; mas a maneira pela qual as partes estão diferentemente incrustadas em pessoas complexas continua a ser fundamental.

Portanto, a noção de "posicionamento", na proposta teórica apresentada por Barth (2000), oferece uma maneira de juntar novamente o que foi desmontado até então e de relacionar as pessoas às múltiplas tradições que elas adotam e que as impulsionam. Pretende-se adotar a noção acima citada durante o trabalho de campo a ser realizado no Doutorado devido ao entendimento também que se tem de que, como sustenta Crapanzano apud Maggie e Rezende (2002), no Brasil, onde a linguagem predominante para interpretar a classificação, a interpretação e a ação social é política, para se entender a retórica de categorias sociais é necessário ter claro "quem fala", "para quem

\footnotetext{
${ }^{5}$ Sobre a noção de estrutura na visão de Claude Lévi-Strauss, recomenda-se a leitura de "A Noção de Estrutura em Etnologia", capítulo pertencente à obra Antropologia Estrutural, publicada no Rio de Janeiro em 1996, em sua quinta edição, pela editora Tempo Brasileiro.
} 
fala" e "de que posição fala", isto porque o autor supracitado considera que "todo estudo sobre raça ou qualquer outro sistema de classificação social deve levar em consideração o modo como tais sistemas determinam as aplicações e manipulações possíveis de suas categorias" (Maggie; Rezende, 2002, p. 20-21).

Procedendo desta maneira, para Crapanzano apud Maggie e Rezende (2002), é possível entender os efeitos sociais e políticos que as aplicações e manipulações acima citadas produzem, uma vez que é na prática e os jogos de retórica que o poder é introduzido nas classificações. Vale salientar que estas classificações, aplicações, manipulações e jogos fazem parte, também, da relação pesquisador/pesquisado ao longo do processo da pesquisa e será também em relação a esta perspectiva que o olhar da pesquisadora estará voltado.

Desta feita, é importante frisar, aqui, que a característica básica do trabalho de campo é estabelecer relações, interações com pessoas concretas, de forma profunda. Compartilha-se, então, com o pensamento de Guber (2005), que aponta que o que a etnografia urbana reflete é uma intersubjetividade, um discurso a partir de uma relação, e não a subjetividade do pesquisador, isto é, as revelações intimistas do autor, suas próprias sensações, seu Eu. O trabalho de campo é concebido como uma experiência de imersão subjetiva, produtora de uma intersubjetividade e é dela que se está em busca.

\section{Referências}

BARTH, Fredrik. A Análise da Cultura nas Sociedades Complexas. In: O Guru, o Iniciador e Outras Variações Antropológicas. Rio de Janeiro, Contra Capa, 2000.

BOURDIEU, Pierre. Introdução a uma Sociologia Reflexiva. In: O Poder Simbólico. Rio de Janeiro: Bertrand Brasil S.A, 1989.

. Um analista do Inconsciente. In: SAYAD, Abdelmalek. A imigração ou os Paradoxos da Alteridade. São Paulo: Editora da Universidade de São Paulo, 1998.

. A Economia das Trocas Simbólicas. São Paulo: Editora Perspectiva S.A, 2001.

CLIFFORD, James. A Experiência Etnográfica: antropologia e literatura no século XX. 2. ed. Rio de Janeiro: Editora UFRJ. 2002.

DA MATTA, Roberto. O ofício do etnólogo, ou com ter "Antropological Blues". In: NUNES, E. (Org). A Aventura Sociológica: objetividade, paixão, improviso e método na pesquisa social. Rio de Janeiro: ZAHAR EDITORES, 1978.

ELIAS, Norbert. Introdução à Sociologia. Lisboa: Edições 70, 1980.

EVANS-PRITCHARD, Edward Evan. Bruxaria, Oráculos e Magia entre os Azande. Rio de Janeiro: Jorge Zahar, 2005.

FREYRE, Gilberto. Casa-Grande \& Senzala. Rio de Janeiro: Schmidt, 1936.

GEERTZ, Clifford. A Interpretação das Culturas. Rio de Janeiro: Zahar, 1978.

Obras e Vidas: o antropólogo como autor. Rio de Janeiro: Editora UFRJ, 2002.

GUBER, Rosana. El Salvaje Metropolitano: Reconstrucción del Conocimiento Social en el Trabajo de Campo. Buenos Aires: Paidós, 2005. 
LACERDA, Eugênio Pascele. Trabalho de Campo e Relativismo: A alteridade como crítica da antropologia. Disponível em: <www.antropologia.com.br >. Mimeo, 2003.

LÉVI-STRAUSS, Claude. A Noção de Estrutura em Etnologia. In: Antropologia Estrutural. Rio de Janeiro: Tempo Brasileiro, 1996.

MAGGIE, Yvonne; REZENDE, Claudia Barcellos (orgs.). Raça como Retórica: A construção da Diferença. Rio de Janeiro: Civilização Brasileira, 2001.

PEIRANO, Mariza. A Favor da Etnografia. Rio de Janeiro: Relume Dumará, 1995.

OLIVEIRA, Roberto Cardoso de. O Trabalho do Antropólogo. 2 ed. Brasília: Paralelo 15; São Paulo: Editora UNESP, 2000.

SILVA, Vagner Gonçalves da. O Antropólogo e sua Magia: Trabalho de Campo e Texto Etnográfico nas Pesquisas Antropológicas sobre Religiões Afro-brasileiras. São Paulo: Editora da Universidade de São Paulo, 2000.

TEIXEIRA, Moema de Poli. Negros em Ascensão Social: Trajetórias de Alunos e Professores Universitários no Rio de Janeiro. Tese de Doutorado. Universidade Federal do Rio de Janeiro. Museu Nacional. Programa de Pós-Graduação em Antropologia Social. Rio de Janeiro. 1998.

ZALUAR, Alba. Teoria e prática do trabalho de campo: alguns problemas. In: CARDOSO, Ruth (Org.). A Aventura Antropológica. 2. ed. São Paulo/SP: Editora Paz e Terra, 1988, p. 107123.

Recebido em: 25/03/2015

Aprovado em: 10/06/2015 